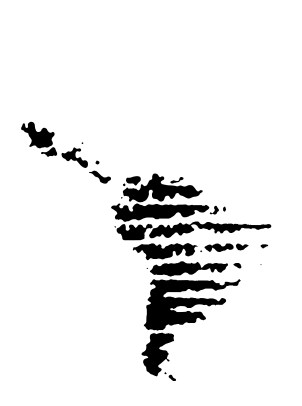

\title{
ALBERTO PATISHTÁN GÓMEZ: RADIOGRAFÍA DE UN INDULTO TARDÍO
}

\section{ALBERTO PATISHTÁN GÓMEZ: RADIOGRAPHY OF A LATE PARDON}

\author{
Osvaldo Antonio Muñoz Vargas*
}

\begin{abstract}
Resumen
El autor muestra el insólito caso de Alberto Patishtán Gómez (Chiapas, México 2000), en cual presenta cronológicamente los hechos que se llevaron a cabo en el paraje Las Lagunas de Las Limas, Municipio de Simojovel. La importancia del caso se da al sobreestimar el relieve de violaciones de proceso en derechos humanos por sobre el trasfondo del derecho penal. En este caso específico, el autor pretende analizarlo desde una perspectiva puramente política, dejando de lado cualquier matiz antropológico de fondo en el cual, ante una relectura, se podría inferir fácilmente que hubo discriminación étnica.
\end{abstract}

Palabras clave: indígena, policías, masacre, indulto, zapatismo.

\begin{abstract}
The autor illustrates the Patishtán Gómez' case (Chiapas, Mexico, 2000), in which the facts that took place at Las Lagunas de Las Limas, Simojovel are shown chronologically. The importance of this case is due to its overestimation of the violations of the human rights process over the depth of the criminal law. In this specific case, the author pretends to analyze it from a strict political viewpoint, leaving any anthropological research behind because by having reread it, it can be easily inferred that there was ethnic discrimination.
\end{abstract}

Keywords: indigenous, policemen, massacre, indult, 'Zapatismo' movement.

\footnotetext{
* Costarricense. Antropólogo sociocultural, comunicador y abogado litigante y especialista de derechos humanos. Investigador de la antropología maya. Curador procesal y perito en Derecho del Poder Judicial de la República de Costa Rica. *El criterio del ensayista no necesariamente coincide con la institución de referencia.
} 
El presidente de México, Enrique Peña Nieto, indultó al profesor indígena tzotzil $^{1}$, Alberto Patishtán Gómez, al reconocer que se violaron sus derechos humanos después de que pasó 13 años en prisión, condenado por el asesinato de siete policías de Chiapas, tras una emboscada. El mandatario instruyó la medida para que Alberto Patishtán Gómez quede libre de forma inmediata (La Nación, 2013, p. 28 A).

En teoría, México ha dado una gran exposición mediática justo cuando el mandatario Peña Nieto impulsó la modificación de la ley penal, en la cual es posible indultar por violaciones a los derechos humanos a una persona sentenciada. El mandatario agregó que Alberto Patishtán, de 42 años, sería el primer beneficiario.

En la práctica, los mismos medios de comunicación (en especial, La Jornada, medio de comunicación escrito que se abocó a indagar detalles desde sus inicios, y en el cual se basa

1 El pueblo tzotzil habita en el centro y centro norte del estado de Chiapas, en el sureste mexicano. Forma parte de la familia mayense junto con otras etnias en los estados de Tabasco, Yucatán, Campeche, Quintana Roo, San Luis Potosí (etnia tenek) y en los países centroamericanos de Guatemala, Belice y Honduras. Se puede ubicar con cierta precisión en los municipios de Amatán, El Bosque, Huitiupán, Simojovel, Chalchihuitán, Pantelhó, Soyalhó, Bochil, Chenalhó, San Andrés Larráinzar, Chamula, Zinacantán, Ixtapa, Acala, Huixtán, San Lucas y San Cristóbal de las Casas. La etnia tzotzil no es homogénea, ya que puede percibirse una primera gran división dada su extensión geográfica: la región tzotzil de los Altos de Chiapas, con clima frío y geografía montañosa y la región tzotzil de la zona baja, con clima tropical y geografía menos accidentada. prioritariamente este ensayo-crónica) han tildado como tardío el indulto presidencial, sobre todo al tomar en consideración los pormenores en torno de esta serie de incidentes sociopolíticos de los cuales se desprende esta historia, teñida de injusticia social.

En efecto, este ensayo intenta recopilar con detalle cada uno de los acontecimientos que giran alrededor de este interesante caso. A continuación, se inicia con la descripción de los hechos que motivaron el encarcelamiento injusto por 13 años de este profesor indígena.

¿Qué aconteció la mañana del lunes 12 de junio de 2000 en el paraje Las Lagunas de Las Limas, Simojovel? ¿Cuál (es) pudo (ieron) ser el móvil (es) de los perpetradores? ¿Qué estaba pasando en esos días?

Tres semanas después de esa fecha se celebrarían los comicios en los que el Partido Revolucionario Institucional (PRI) perdería la Presidencia. El presidente Ernesto Zedillo, conocedor del desarrollo de la guerra contra los indígenas de Chiapas, y de los de El Bosque, estaría de visita el martes 13 de junio del año 2000 para inaugurar una carretera en la selva Lacandona, pero suspendió la gira. El Ejército federal envió muchos efectivos, ocupó el lugar de la emboscada, la cabecera municipal, los caminos, y se adentró en las comunidades zapatistas. Sin embargo, la primera hipótesis de la Secretaría de la Defensa Nacional fue que podía tratarse de una concentración del Ejército 
Popular Revolucionario (EPR) (La Jornada 13/06/2000 Citado por Mariscal, 2000), algo que sorprendió pues este nunca había estado presente en la zona.

Ese mismo día, la Central Independiente de Obreros Agrícolas y Campesinos (CIOAC) sostuvo que los responsables de los asesinatos pudieron haber sido paramilitares del Mira (aunque visto en perspectiva, el grupo paramilitar en El Bosque era conocido como Los Plátanos, por el nombre de la comunidad donde se asentaban, junto con policías judiciales, desde donde habían salido el 10 de junio de 1998 para participar en la masacre de zapatistas en Unión Progreso, en Los Plátanos). La policía federal también habló de narcotraficantes. Para nadie era un secreto el trasiego de marihuana.

La masacre fue un lunes. El sábado anterior los zapatistas habían conmemorado el segundo aniversario de lo ocurrido en Unión Progreso y Chavajeval, y el encarcelamiento de las autoridades autónomas de San Juan de la Libertad. Diego Cadenas, joven abogado del Frayba, declaró a La Jornada el día de la emboscada que ese 10 de junio, cuando viajaba a Unión Progreso para participar en los actos religiosos por el segundo aniversario de la masacre de 1998, en los retenes militares de Puerto Caté y San Andrés Larráinzar, los militares le dijeron que estaban suspendidas las garantías individuales, lo cual no era cierto.

Dos días después, un comando de entre 10 y 15 individuos, con armas de alto poder, emboscó el carro pick-up verde en que se trasladaban, procedentes del Municipio Simojovel, ocho policías y el chofer oficial del ayuntamiento de El Bosque, persona menor de edad e hijo del alcalde Manuel Gómez Ruiz. Herido de gravedad, el joven Rosemberg Gómez Pérez, quien conducía el vehículo con los dos comandantes en la cabina, y el agente de Seguridad Pública Belisario Gómez Pérez habrían sido asesinados por los atacantes.

La Jornada informaba también que en lo que iba del año 2000, esta era la octava emboscada. Los ataques ya habían dejado 20 muertos y un número igual de heridos. Los policías asesinados en Las Lagunas fueron Francisco Escobar Sánchez, Rodolfo Gómez Domínguez, Guadalupe Margarito Rodríguez Félix, Arbey Vázquez Gómez y Francisco Pérez Mendoza. Dos de ellos todavía hoy son recordados por las cruces de cemento donde fueron brutalmente acribillados. En total, se contaron 85 impactos de AK-47 y R-15.

\section{El Ejército Zapatista de Liberación Nacional (EZLN) se deslinda e investiga}

Un día después de la emboscada, el Comité Clandestino Revolucionario Indígena, Comandancia General del EZLN extendió este comunicado:

De acuerdo con los datos, el ataque fue realizado con tácticas de narcotraficantes, paramilitares o militares. El uso del llamado 'tiro de gracia' es 
recurrente en estos grupos armados. El ataque se realizó en una zona saturada de tropas gubernamentales (Ejército y policía), en la que es muy difícil que se pueda movilizar un grupo armado sin ser detectado y sin la complicidad de las autoridades. El grupo atacante contaba con información privilegiada sobre los movimientos y número de personas emboscadas. Dicha información sólo podría ser obtenida por gente del gobierno o cercana a él. ${ }^{2}$

La comandancia rebelde señaló:

El EZLN está investigando para esclarecer la identidad y motivos del grupo atacante. Todo apunta a que fueron del gobierno (o con el auspicio gubernamental) las personas que realizaron la agresión, ya que así tendrían el pretexto para aumentar la militarización en Chiapas, y para justificar el ataque a comunidades zapatistas o al EZLN. Es de notar que este hecho refuerza el clima de inestabilidad con el que amenaza el candidato oficial si no gana. ${ }^{3}$

El hecho cruel y violento es ya un argumento para aumentar la presencia militar en el estado, incluso en zonas muy alejadas del lugar, detallando que se han reforzado aún más los cuarteles federales de Guadalupe Tepeyac, en Las Margaritas; Cuxuljá, en Ocosingo; Caté, en El Bosque, y las cabeceras municipales de Simojovel y El Bosque. Asimismo, el número de aeronaves

2 Comandancia General del Ejército Zapatista de Liberación Nacional, 2013.

3 Idem. artilladas y de sus sobrevuelos en las zonas Altos, Selva y Norte aumentó. El EZLN se desvincula de este acto y le pide a la opinión pública que no se deje engañar.

\section{El destino de Patishtán}

El gobierno estatal de Roberto Albores Guillén, por medio de su procurador Eduardo Montoya Liévano, acogió la hipótesis de que los atacantes pudieron ser zapatistas, en venganza por la masacre contra ellos ordenada por el propio Albores Guillén en 1998, aunque también reconoce que pudieron haber sido asaltantes.

El senador Carlos Payán Velver, miembro de la Comisión de Concordia y Pacificación (Cocopa), propuso que la instancia legislativa viajara a la entidad, pues la situación era muy grave (La Jornada 14/6/2000 citado por Bellinghausen, 2013). En la misma fecha, Víctor Manuel Pérez López, dirigente de la CIOAC, reveló que el gobierno de Chiapas armó y financió en 1997 a disidentes del Partido del Trabajo para combatir al gobierno municipal de dicho partido y la CIOAC. Cualquiera en la zona sabe quiénes son y que una vez cumplido el objetivo de devolver al PRI la alcaldía, estos se dedicaron al asalto y el narcotráfico. Ellos actúan en la impunidad, a la luz del día, incluso cuando militares y policías realizan patrullajes continuos.

Para entonces, en dos emboscadas previas, habían sido asesinadas cuatro 
personas, según la CIOAC. El 13 de enero de 2000, en el camino a Chavajeval, fue asesinado Martín Sánchez Hernández por encapuchados y armados, y luego, el primero de febrero de ese mismo año, Rodolfo Gómez Ruiz, Lorenzo Pérez Hernández y Martín Gómez, todos tzotziles.

Diputados del Partido de la Revolución Democrática (PRD) y el Partido Acción Nacional (PAN) acusaron de negligencia al secretario de Gobierno Mario Lescieur Talavera, y dijeron que la emboscada serviría de pretexto para la llegada de más elementos de la Policía Federal Preventiva. Los tanques, helicópteros y artillería del Ejército federal ya habían llegado.

El episodio demostraba descontrol. El gobierno creyó lograrlo, así que el mandatario Zedillo pudo viajar el 19 de junio a Marqués de Comillas para inaugurar su carretera. Ese mismo día, en la cabecera municipal de El Bosque, el Ejército y la Policía Federal Preventiva (PFP) capturaron, sin mostrar orden de aprehensión, al profesor Alberto Patishtán Gómez. Un grupo de pobladores, identificados como miembros del PRI (La Jornada, 20/6/2000), ${ }^{4}$ solicitaron la intervención del Congreso estatal, sostuvieron que el detenido era inocente, se deslindaron de los hechos violentos del 12 de junio, y argumentaron no estar armados ni pertenecer a ningún grupo paramilitar. No les hicieron caso, más bien los amenazaron.

4 Idem.
Patishtán estuvo ilegal por un mes en el Hotel Safari de Tuxtla Gutiérrez. Sus familiares, amigos y correligionarios ocuparon la presidencia municipal y demandaron la libertad del profesor. $\mathrm{Ni}$ siquiera su propio partido los respaldó. El entonces diputado priista Ramiro Miceli Maza, compadre del alcalde, o sea padrino de bautizo del joven Rosemberg, resultó ser pieza clave para inculpar al líder comunitario, quien fue encarcelado en el centro penal de Cerro Hueco.

También aquel 19 de junio, respecto a los comicios del 3 de julio de 2000, el subcomandante Marcos escribió:

Mientras tanto, acá estamos temblando. Y no porque el 'croquetas' Albores haya contratado al Alazraki para que le 'levante' su imagen (probablemente Albores ya busca chamba en la promoción de alimento para perros), ni por los seiscientos mil dólares que le va a pagar (con dinero destinado originalmente a 'resolver las condiciones de pobreza y marginación de los indígenas chiapanecos', Zedillo dixit). Tampoco por los ladridos del 'cachorro' Montoya Liévano (más que ahora está nervioso porque ya se está descubriendo que fueron sus 'muchachos' -es decir, sus paramilitares- los responsables del ataque a la Seguridad Pública en El Bosque, el pasado 12 de junio). No, estamos temblando porque estamos empapados por la lluvia. Y es que, entre helicópteros y tormentas, no encuentra uno buen techo. ${ }^{5}$

5 Idem. 


\section{Anti-zapatistas}

El 10 de julio siguiente, una vez pasados los comicios federales, un mes después de la emboscada, la policía estatal detuvo en Bochil a dos bases de apoyo del EZLN residentes de Unión Progreso, y los acusó de participar en el crimen. Aunque la Procuraduría General de la República (PGJE) sostenía que los atacantes habían sido un grupo de priistas disidentes, entre ellos Patishtán; estos cruzaban acusaciones con el alcalde Manuel Gómez Pérez, a quien impugnaban desde meses atrás por corrupción.

La Procuraduría General de Justicia del Estado (PGJE) tenía sus propias líneas de investigación. Con apoyo de la policía destacada en Los Plátanos, las autoridades sembraron evidencias de delito en dos indígenas de Unión Progreso. Uno de ellos, Salvador López González, torturado e interrogado sin traductor, firmó una declaración inculpatoria ad hoc y fue encarcelado. En prisión se encontró con su coacusado: Patishtán. Sin conocerse entre ellos, ambos cargaron con todo el peso sociolegal de la emboscada.

\section{La Jomada informó desde Unión Progreso:}

El destacamento policíaco que detuvo a los zapatistas ha tenido a la vista, durante largo tiempo, los cultivos de marihuana que hay en Los Plátanos. La violencia interna en esa población, controlada por un conocido grupo paramilitar, ha servido siempre de pretexto para acusar y atacar a los vecinos zapatistas. Según el representante de Unión Progreso, 'nos acusan de lo que ellos hacen'. El Ejército federal ha ingresado a Los Plátanos para destruir estos plantíos, los únicos detectados en la región. $\mathrm{Al}$ menos en dos ocasiones, aunque sin detenidos. ${ }^{6}$

Salvador y su hermano Manuel fueron tomados el 10 de julio; sus familiares declararon:

Los de Seguridad Pública (SP) los golpearon, descalzaron y desnudaron, y dejaron inconsciente a Salvador. Con los detenidos se encontraban un niño (que lloraba mucho) y un adolescente, quienes vinieron a avisar que a los compañeros se los habían llevado.?

Como los captores no eran de Bochil sino de El Bosque, alquilaron la cárcel por un tiempo. Después los detenidos fueron enviados a Cerro Hueco. Los de la Secretaría de Seguridad Pública (SP) les pusieron un poco de marihuana y un puñito de bala y les robaron 28 cajas de refrescos. Manuel sería pronto liberado.

El 10 de junio, horas antes de la matanza de policías, la Seguridad Pública en Los Plátanos interceptó una camioneta de Unión Progreso. El chofer era el mismo Salvador. Lo interrogaron sobre una lista de nombres. Desde entonces querían culpar a los compañeros, declaró un representante de su comunidad: 
'No sabemos cuántos están en la lista. A lo mejor estamos acusados todos.'

Con dos chivos expiatorios, Alberto (Patishtán) y Salvador, el caso empezaba a ser resuelto, o al menos dejado de lado por los medios de comunicación nacionales.

\section{IV. "Cuando detuvieron al profe Patishtán, nadie lo creyó"}

Desde el primer día, el 19 de junio de 2000, se pensó que Alberto Patishtán estaba secuestrado, recuerda el también maestro Martín Ramírez López, uno de los que no han dejado de gritar la inocencia del profesor.

Resulta útil ir más allá de la reconstrucción forense de la matanza (y el robo de unas armas que nunca aparecieron), y de la relación cronológica entre los hechos y las actividades de Patishtán ese día, con testigos consistentes que lo ubican en Simojovel y Huitiupán; con excepción de uno, Rosemberg Gómez Pérez. Éste, herido y entre cadáveres, identificó por la voz, según su declaración del 15 de junio, a uno de los atacantes armado y encapuchado, y resultó ser el profesor bilingüe y público opositor de su papá, el entonces alcalde Manuel Gómez Ruiz; sí, el líder comunitario de integridad reconocido hasta por quienes, fuera del PRI, estaban entonces en la resistencia, como era el caso del profesor Martín y muchos más.

Patishtán acababa de acudir a la capital del estado, con un grupo de indígenas, a demostrar con documentos la corrupción en el ayuntamiento de este municipio. Él tenía una jefatura magisterial y organizaba con respaldo de distintos barrios de la localidad una de aquellas sociedades productivas oficialistas denominadas triple $\mathrm{S}$ o SSS. Cuando lo detuvieron, nadie lo creyó, recuerda Ramírez López. Centenares de personas salieron a la calle, ocuparon la alcaldía y mandaron una delegación a Tuxtla Gutiérrez, de paga (eran priístas), que fue neutralizada por el gobierno, y otra de voluntarios, que sí presionó y logró una minuta sobre su liberación.

El gobernador Roberto Albores Guillén prometió que liberaría al profesor. Al no cumplir, los indígenas insistieron fuertemente, y se les amenazó con culparlos también del crimen. Muchos otros se acobardaron. Con la amenaza del presidente municipal salieron corriendo, refiere Ramírez López. Había unos seis maestros que continuaban insistiendo, junto con la esposa de $\mathrm{Pa}$ tishtán. Con el tiempo, ella se cansó y lo abandonó, pero eso ya es parte del daño personal causado por los años posteriores de cárcel.

En mayo de 2000, un mes antes de la emboscada en un paraje de Las Limas, municipio de Simojovel, los priistas inconformes entregaron un documento que sólo pudo ser escrito por Patishtán, y el edil lo vio como un peligro. Según el profesor Martín, ya estaba a punto de caer, ya no bastaba la protección del diputado Ramiro Miceli Maza ni del gobierno de Albores Guillén. Así 
que lo salvó la masacre, y más aún la aprehensión de su principal crítico y denunciante. El peligro era Patishtán, no el movimiento opositor. Estando él en la cárcel, la protesta se esfumó.

El desaseo ministerial en las primeras declaraciones que lo inculpaban (del policía sobreviviente Belisario Gómez Pérez y el joven Rosemberg, del alcalde y de otro profesor, Martín Gómez Culebro, 14 y 15 de junio), así como las de policías municipales a quienes se indujo abiertamente la mención de Patishtán como atacante, y aun la declaración del diputado Miceli Maza (19 de junio, día de la aprehensión del acusado), no impidieron que se dieran por buenas en los tribunales. Y se estiraron milagrosamente para inculpar, un mes después, al transportista base de apoyo del EZLN Salvador López González.

La gente siempre supo que Gómez Culebro se prestó a falsificar sus declaraciones por órdenes del presidente municipal. Ya luego él ha dicho que nunca declaró, que le habían inventado todo, comenta Ramírez López.

El Bosque es un pueblo pequeño. Todos se conocen. Actualmente, el exalcalde Gómez Ruiz y su hijo Rosemberg viven enfrente de la familia Patishtán. La madre de Alberto, María, prima hermana de Gómez Ruiz, es una persona muy enferma y no participa mucho en el movimiento actual por la liberación de su hijo, que en El Bosque cuenta con centenares de seguidores, incluidos los hermanos de María, Carmen, Julia,
Manuela, Demetrio de Jesús y Juan, todos Gómez Gómez, y sus cuñadas Andrea y María. Los respaldan la mayor parte del magisterio oficial, las iglesias, comerciantes, familias, incluso niños y jóvenes que no conocen aún al profesor.

Muchos recuerdan cómo era Rosemberg antes de la emboscada a la que sobrevivió. De 15 o 16 años, era considerado un intocable. Llevaba una escolta en todas las fiestas y ferias a las que gustaba ir. Por esa razón, andaba siempre con los policías, muy cuidado, comenta otro miembro del movimiento ciudadano de El Bosque que insiste en la inocencia del profesor. Comienzan a llegar varios indígenas, campesinos y mujeres con su hermosa vestimenta tradicional, para una reunión en el sitio donde Ramírez López habla con La Jornada.

La Jornada recogió hace algunos años un testimonio según el cual el propio Rosemberg habría expresado arrepentimiento por lo que le hicieron al profesor (su primo, por cierto), y confesó que por su declaración fue recompensado con una camioneta nueva.

\section{Olvido...}

Cuatro gobernadores (Albores Guillén, Salazar Mendiguchía, Juan Sabines Guerrero y Manuel Velasco Coello) se han pronunciado por la liberación del profesor.

El zapatista Salvador López González fue liberado durante el mandato de 
Salazar Mendiguchía -quien como candidato se comprometió a liberar a Patishtán-; heredaba de Albores Guillén y el gobierno zedillista muchos presos del EZLN, y terminó liberándolos a todos. Así resultó que un acusado por la matanza de policías fue liberado con base en inconsistencias en las declaraciones ministeriales del segundo sobreviviente, Belisario Gómez Pérez. Lo que los jueces consideraron insostenible para el caso de Salvador lo dieron por bueno para condenar reiteradamente entre 2002 y 2004, más allá de amparos y apelaciones, al profesor, líder comunitario y activista de los derechos humanos en las prisiones chiapanecas. Seguidamente, el expolicía Belisario, al igual que las viudas de los demás policías, desaparecieron, y ni siquiera se puede demostrar que hayan sido indemnizados adecuadamente.

\section{VI. ¿Por qué Patishtán estuvo preso más de una década?}

Desde 2007, una pregunta es constante entre abogados, obispos, activistas de derechos humanos y observadores del proceso jurídico de Alberto Patishtán Gómez: si es tan clara la evidencia de que él no participó en la emboscada que costó la vida de siete policías entre El Bosque y Simojovel el 12 de junio de 2000, ¿por qué seguía preso? Si casos más flagrantes, pero con procesos basados en montajes, al ser confrontados por la Suprema Corte de Justicia de la Nación (SCJN) derivaron en la libertad de criminales capturados in fraganti, ¿qué impedía que el profesor salga libre?
¿A quién beneficia su encarcelamiento? ¿A quién (es) afectaría su absolución?

¿Por qué no surtió ningún efecto el interés de Margarita Zavala, esposa del expresidente Felipe Calderón, quien en dos ocasiones recibió a familiares de $\mathrm{Pa}$ tishtán y les aseguró que haría lo posible por obtener la justicia para el profesor?

Según se desprende de lo ocurrido hace cerca de 13 años en un paraje carretero en el norte de los Altos de Chiapas (La Jornada, 22 y 23 de marzo citado por Bellinghausen, 2013), y los efectos paralelos-la fabricación de cargos y la coacción contra cualquier resistencia-, habría que empezar buscando la razón en el gobierno estatal. Aunque por la gravedad de los delitos imputados se trata de un caso federal, su elaboración judicial y administración posterior han corrido a cargo de autoridades estatales, con exclusión del periodo en que $\mathrm{Pa}$ tishtán fue enviado a un penal federal en Guasave, Sinaloa, por solicitud del secretario de Gobierno sabinista, y ahora velasquista, Noé Castañón León.

En 2000, el mandatario estatal, interino de otro interino, era Roberto Albores Guillén, quien llegó al cargo después de la matanza de Acteal. Para el tiempo de la masacre de sus agentes, tenía ya graves cuentas pendientes con el municipio oficial El Bosque y el autónomo San Juan de la Libertad. Semanas después del crimen, su partido, el PRI, perdió las elecciones. No obstante, nunca dejó de tener poder, pese a los pobres intentos de su sucesor, Pablo Salazar 
Mendiguchía, por investigarlo. Con la llegada de Juan Sabines Guerrero, Albores Guillén recuperó espacio y pudo ver preso a su sucesor. Hoy, su hijo del mismo nombre, es senador de la República, miembro de la Cocopa y precandidato para gobernador.

El actual Secretario de Gobierno, Noé Castañón León, a cargo de la política interna de la entidad desde hace cuatro años, miembro del grupo político de Albores Guillén y padre del actual líder del Congreso estatal, del mismo nombre, presidía el Supremo Tribunal de Justicia del Estado (STJE) durante la captura, proceso y encarcelamiento de Patishtán. Como magistrado, también apoyó la remunicipalización de facto en las llamadas zonas de influencia del EZLN. Se le recuerda como uno de los orquestadores de las deserciones de presuntos zapatistas (impostores y hasta delincuentes), con todo y entrega de armas, en horario estelar televisivo entre 1999 y 2000, en escenarios naturales.

El actual Secretario de Gobierno ocupó la titularidad del STJE de 1995 a 2001, años complejos en Chiapas. Sobrevivió a tres gobernadores (Javier López Moreno, Julio César Ruiz Ferro y Albores Guillén); el cuarto, Salazar Mendiguchía, antes del primer año de su gobierno lo acusó de peculado, abuso de confianza y otros delitos que habría cometido durante la administración precedente. No prosperaron las cuatro averiguaciones previas que le iniciaron, pero fue destituido y dejó la entidad en diciembre de 2001. Volvería como secretario de Gobierno de Sabines Guerrero en 2009, cargo que mantiene con Manuel Velasco Coello.

\section{Consideraciones finales}

- $\quad$ El caso en estudio, de primera entrada, pareciera un asunto de tema común, en el nivel latinoamericano, y aminorado en cuanto a violaciones generales de derechos humanos. No obstante, el caso contiene fuertes componentes políticos y culturales en un México enfermo, principalmente en sus estructuras políticas, con escenografía principal de zonas pobres y olvidadas.

- La corrupción municipal y/o local identifica un grado de organización delincuencial importante. A pesar del trasfondo penal del caso que se presenta, a simple vista, se justifica este tema en una débil plataforma de derechos humanos, en el cual, una vez más, se entretejen la arbitrariedad y la injusticia hacia los sectores más vulnerables de la población.

- El caso también saca a flote, a grandes rasgos, las marañas políticas por acallar cualquier intento de protesta y de lucha ideológica ante un oficialismo corrupto a nivel local. La lucha parece estar estratégicamente individualizada en un cobarde ataque a un indígena preparado y académico. 
- Como delito continuado, en el gran abanico de casos sobre derechos humanos en las latitudes latinoamericanas, se patentiza la desigualdad procesal de una de las partes en el escenario judicial dado. En el encuadre periodístico se resume esta situación de esta forma: 'El profesor no tuvo acceso a un abogado defensor competente, un fiscal independiente o un juez imparcial.'

- La crítica mediática más importante por resaltar es sobre la decisión aleatoria del indulto. La Jornada, medio vocero clave en este proceso, no ha mermado ningún esfuerzo para presentar un México políticamente arbitrario, erosionado en sus bases judiciales y tardío de una justicia pronta y cumplida, los íconos más significativos de un sistema democrático.

\section{Referencias}

Bellinghausen, H. (2013). Caso Patishtán: ¿Qué aconteció la mañana del lunes 12 de junio de 2000 en el paraje Las Lagunas de Las Limas, Simojovel? Recuperado de http:// www.proyectoambulante.org/index.php/ noticias/nacionales/item/1934-caso-patishtan-que-sucedio-la-manana-del-12-dejunio-del-2000-en-el-paraje-las-lagunasde-las-limas
Bellinghausen, H. (2013). Pese su clara inocencia, ¿por qué sigue preso Patishtán?, claman sus abogados. Recuperado de http://chacatorex.blogspot.com/2013/03/pese-suclara-inocencia-por-que-sigue.html

Comandancia General del Ejército Zapatista de Liberación Nacional (2013). Comunicado del Comité Clandestino Revolucionario Indígena. Recuperado de http://palabra.ezln.org.mx/comunicados/2000/2000_06_13.htm

Cronología Proceso Alberto Patishtan Gómez (30 de octubre del 2013). Periódico El Universal. Recuperado de http://archivo. eluniversal.com.mx/estados/2013/cronologia-alberto-patishtan-gomez-961771.html

Mariscal, Á. (13 de junio del 2000). Grupo Armado embosca a policías en Chiapas; siete, los muertos. La Jornada. Recuperado de http://www.jornada.unam. $\mathrm{mx} / 2000 / 06 / 13 /$ matan.html

México AP-Sección Mundo (1 de noviembre del 2013). Indultan a indígena en México, víctima de proceso judicial irregular. La Nación, p. 28 A. Recuperado de http:// www.nacion.com/mundo/latinoamerica/ Indultan-indigena-Mexico-judicial-irregular_0_1375662438.html

Patisthán, A. (2013). 'Estoy vivo, soy libre, seguiré luchando...' Recuperado de http:// albertopatishtan.blogspot.com/2013/11/estoy-vivo-soy-libre-seguire-luchando.html.

Recibido: 9/11/2014 • Aceptado: 25/2/2016 


\section{ANEXO N. 1}

\section{En carne propia: ¡ $\mathrm{Al}$ fin, libertad! ${ }^{8}$}

Antes que nada, compañeros, compañeras y todos los medios de comunicación: les doy las gracias por estar en este momento y espero que estas palabras, que las voy a expresar dentro de lo más profundo de mi corazón, que así se diga.

¿Quién es Patishtán? Patishtán soy yo. Soy una persona que no solamente oigo, sino que escucho. ¿Quién es Patishtán? Es uno que está perdiendo la vista por mi enfermedad. Al parecer como que ya no me deja ver tanto con los ojos, pero sí los veo mucho más claro en mi corazón.

Eso es si quieren tener la definición de quién es Patishtán. Es uno que no solamente vio lo que estaba pasando, no solamente quedó mirando y viendo lo que estaba pasando en su pueblo en aquellos años. En aquellos años en los que realmente nuestros gobernantes han dicho, o hemos dicho, que ya no hay esclavitud. Sin embargo, en aquel tiempo me topé con que sí se estaba dando otro tipo de esclavitud. Aquellos tiempos entonces, como hoy en día todavía se repite, existe el olvido y la marginación de los pobres. Solamente que muchas veces nuestras autoridades voltean a ver a aquellos que sí tienen el poder económico.

En aquellos tiempos, entonces, la gente sufría, la gente carecía de muchas cosas.

8 Patishtán, 2013.
La gente que no habla el español, la gente que no podía escribir, en aquellos tiempos entonces del año 2000, y mucho más antes, para aquella gente pobre, para aquella gente humilde e ignorante, se refugiaba, o se refugiaban con aquella persona que sabe un poco más o menos leer algún documento o puede expresarse.

Entonces, en aquel tiempo, me acuerdo que me topé y me topo con una autoridad tan autoritario o tirano, como se lo puede llamar otras palabras. Quiso esclavizar a la gente y acabarla en vida. Yo estaba viendo lo que estaba pasando y dije: "Hasta aquí no más. Tengo que salir a defender este pueblo mío", como decía mi hijo. "No me queda de otra", decía yo. Alguien tiene que salir por ellos, y decía yo: "voy a asumirlo".

Y salí a defender a mi pueblo en aquel tiempo, cuando el presidente municipal, de nombre Manuel Gómez Ruíz había hecho tantas cosas. Y yo salí a la defensa, salí a gritar, salí a levantar la mano. Eso fue la causa de que me mandaron hasta la cárcel. Tenemos documentos en archivos donde nosotros estamos pidiendo la destitución del presidente municipal en aquel tiempo. A finales del mes de mayo, me acuerdo, ya estaba todo listo para destituir al presidente municipal, a este que estaba haciendo los malos actos contra la gente pobre.

Pero después de quince días entonces cuando ya nosotros y el pueblo de El Bosque estábamos para destituir a esta autoridad tan autoritaria, sucede una 
emboscada de la que ustedes ya sabrán. A consecuencia de eso es que entonces me llevan a la cárcel, y no solamente me llevan sino que me sentencian con una condena a muerte. Me querían acabar, pero yo soy inocente ante los ojos de Dios y ante mí mismo.

En el primer día que llego en la cárcel decía yo: "Aquí comienza una tarea más de mi vida. No puedo aceptar estas cosas." Y así entonces se originó mi encarcelamiento por defender al pueblo oprimido. Porque no solamente anunciaba las cosas buenas de mi pueblo, sino que también denuncié lo que estaba pasando en mi pueblo. Y por esas personas que siempre tienen el poder para joder, eso fue lo que me hicieron: hacerme acabar en la cárcel.

Pero gracias a Dios estoy vivo, no estoy muerto, y tengo muchas cosas por hacer. Como decía mi hija Gaby, a ella y a mi hijo Héctor, que están aquí, no los vi crecer. Pero algo agarraron de esa semilla que yo tenía y eso es lo muy importante para mí: que esa semilla que al parecer escondieron, pero estos jóvenes que tengo a mi lado supieron sembrar y germinarlo y hoy los frutos los estoy viendo y los estamos viendo todos. Eso es para mí muy importante.

Quisieron acabar mi lucha. Quisieron hacerla restar, pero lo que pasó fue multiplicar. Quisieron ocultarla y lo que hizo fue resplandecer. Así fue la cosa.

Llego a la cárcel entonces, y veo nuevamente, y me encuentro con compañeros presos y presas que para mí fue mi pueblo, nada más que diferente. Me sacaron de mi pueblo y me mandan a otro pueblo, a otra cárcel. Porque allá me topo con otros compañeros pobres, unos compañeros que aquí están ahora presentes también, y con ellos vivíamos dentro de la cárcel una gran injusticia. Entonces, dije yo, el trabajo no termina, y por acá comienzo nuevamente a luchar. Y eso fue lo que hice.

Encontré en la cárcel humillaciones, encontré que la gente pobre, que la gente indígena, que no sabe defenderse, que no tiene dinero para pagar a un abogado y que no tiene intérprete, pues que se queda en la cárcel. ¡No! Yo tengo que hacer algo por ellos, dije. Luché en muchos momentos. Encontré caras tristes en la cárcel. Encontré llantos, que muchas veces por ello tuve que empeñarme de ser muchas cosas en muchas ocasiones.

Tuve que ser sacerdote, aunque no lo soy, porque tuve que obrar por los enfermos. Muchas veces tuve que ser psicólogo para dar terapias a aquellos que se sentían destrozados. Tuve que tomar el papel de abogado, aunque no lo soy, porque muchos me preguntaban, aquellos que perdían un amparo o algo o cuando lo sentenciaban y me decían: "Patishtán, qué sigue de esto". Y yo, que no soy abogado, pero más o menos he visto de mi experiencia, les decía yo: "Esto hay que seguir. Así es".

Por último, aunque fue mucho, tuve que empeñarme en ser doctor, y no lo 
soy, pero es que muchos de mis hermanos indígenas llegaban conmigo y me decían: "Qué hay que tomar, Patishtán, cuando duele a uno la cabeza o duele el estómago". Y yo les decía: "Pues esto hay que tomarlo". Y a ese punto tuve que llegar. Y es que así es.

En la cárcel entonces mucha gente, o también nuestras autoridades, nos dicen: "Aquí ya acabó el derecho, aquí ya no hay nada que hacer". Y yo decía: "Aquí hay mucho que hacer. Aquí voy a comenzar a hacer algo, aquí tengo que aprender no tanto para enseñar, porque por más que uno sepa, no llega a terminar ni a concluir". Así fue entonces que yo tuve que andar por esos caminos.

¿Pero qué pasa cuando la persona lucha dentro de la cárcel? Entonces no somos bien vistos dentro de la cárcel. Somos estorbo dentro de la cárcel. No somos el bien. Nosotros le llamamos cosa buena, cosa sagrada. Pero la autoridad ve mal lo bueno que hacemos. Quieren que las cosas que hacen lo malo que nosotros les apreciemos. Y no se puede apreciar. A lo bueno, aquellos le llaman mal, y lo mal aquellos le llaman bien. ¿Cómo lo ven? Está todo al revés.

Por esas cosas que anduve haciendo, de andar haciendo las cosas buenas, me decían: "Este hombre hay que sacarlo de esta cárcel, este hombre estorba". Y me mandan de una cárcel a otra cárcel. Y que me tenían de plano ya ni sé cómo se llama, y que por fin me llevan, me mandan. De que te pregunten si quieres ir, no te van a preguntar.
Me mandan entonces a Guasave, el Cereso que yo mismo fui a estrenarlo, hasta eso. Ahí estuve, ahí hay mucha gente y también podemos decir que, como siempre, a los que están en la cárcel los tachamos a veces de delincuentes. Ya sé, pero no todos. Tenemos la mitad que sí la cometió y la otra mitad estamos de pilón, pagando los platos rotos que otros deberían de pagar y que los hacen pagar a la fuerza. Me llevaron allá para acabarme. Esa cárcel la bautizamos nosotros: "el cementerio de los vivos", pues es un lugar donde te quieren matar. Pero yo aprendí más a vivir allá otra vez. Y vieron que no pudieron, y gracias a Dios y por todos los compañeros que están a mi lado y los que no los veo, gracias a ellos tuvieron que regresarme a la misma cárcel de donde me habían sacado. Esto fue lo que pasó.

Y hasta les digo desde este lugar: nunca había yo subido a un avión, ese fue mi estreno cuando me llevaron a Guasave. Pero llegué siempre con una misión: ayudar a aquellos que están en Guasave, mucha gente de dolor, de soledad, de angustia, llámese como le quieran llamar. Yo también fui útil desde esa cárcel. Organicé.

Claro que fue poco, lo importante no es la cantidad sino la calidad y que se haga con amor las cosas. Eso fue lo que hice allá. Ahora ¿qué significa la libertad? Yo desde un principio la libertad la sentí, desde el primer día que llegué a la cárcel estoy libre. Y me he sentido libre siempre. Unas personas amigos 
me preguntaban: "¿Qué es lo que te mantiene que no dejas de reír?" Y yo les digo, es que estoy limpio en conciencia. $\mathrm{Y}$ ante los ojos de Dios me bendice siempre. Y con esa bendición que tengo, decía yo, tengo que contagiar a los demás. Si dejo de reírme un día, les decía a los compañeros, siento que es un día perdido para mí. Por eso si me ven así muy sonriente cada rato no se preocupen, porque eso es mi profesión.

¿Qué le puedo decir a aquella gente que me apoyó y me sigue apoyando? Uno, decirle que tenemos siempre una misión al venir a este mundo. Siempre somos útiles. Desde muy pequeños, al nacer, los aprecian en su mamá. Pero ojalá que cuando nos vayamos a despedir de este mundo igual nos hagan. Que entonces digan: "esta persona hizo esto".

Entonces recuerdos buenos hay que dejar. Pero qué triste sería que hagamos todas las cosas por otro lado. La gente tal vez podría decir: "Qué bueno que se fue de por sí, estorbaba aquí en este mundo". Pero cuando hacemos todas las cosas buenas, yo sé, eso de que hay que esperar que nos paguen, y no hay que buscar eso. Hay que dar las cosas sin condición. Sin esperar nada a cambio. Lo único que les puedo dar aquella gente. Hay mucha gente así a nivel nacional, a nivel internacional.

¿Qué más les puedo decir? Gracias, y sigamos construyendo. Nos falta mucho. Pero lo importante es que no estamos comenzando: solamente hay que continuar. Y otra: el regalo que yo les puedo dar a ustedes en especial, y a todos los demás, es que nos aprendamos a amar los unos a los otros. Es eso. Podrán decir me ustedes: "con eso no basta”. Pues es que, para mí, está la clave ahí.

Algo más les quiero decir en este momento: como ya dijeron algunos compañeros, la autoridad y ustedes han escuchado hoy el indulto. Yo, como siempre he dicho, he sido libre desde un principio y hasta hoy en día. No me están dando la libertad por el delito, sino por las graves violaciones que se vieron y porque estuvo manipulado todo mi proceso. En eso está y por eso aquí sigo y seguiré.

Yo digo en esta hora y en este momento: "mi misión solamente Dios sabrá en mí qué voy a hacer, pero motivos hay para seguir caminando y reclamar justicia. Siempre les he dicho una cosa: momentos no faltan, es lo que sobra". Y como un último agregado quiero decirles que siempre digamos la verdad. Sea con quien sea, digamos la verdad, porque si no perdemos credibilidad en nosotros mismos.

Eso sería todo. Mucho ánimo a todos ustedes y gracias a todos. 


\section{ANEXO N. 2}

\section{Radiografía de los hechos: Momento a momento ${ }^{9}$}

De la emboscada sólo sobreviven Rosemberg Gómez Pérez, hijo del alcalde y el policía estatal Belisario Gómez Pérez. Las primeras especulaciones fueron que todo había sido obra del Ejército Zapatista de Liberación Nacional (EZLN) o miembros del Ejército Popular Revolucionario.

19 de junio 2000.- Es capturado el profesor indígena bilingüe Alberto Patishtán, a pesar de que en las declaraciones, sus testigos admitían que Alberto había estado en el pueblo impartiendo clases, la justicia le dictó una condena de 60 años de prisión.

29 de marzo 2010.- El Movimiento Campesino Independiente (Mocri) de la Coordinadora Nacional Plan de Ayala (CNPA) reporta el inicio de un ayuno de 30 de sus militantes presos en cinco penales de Chiapas en demanda de su libertad. La vocera de la organización informa que las protestas se dan en los penales de Cintalapa, Copainalá, Comitán, San Cristóbal de las Casas y Villaflores. Entre los presos en ayuno está Alberto Patishtán Gómez.

20 de octubre 2011.- La Secretaría de Seguridad Pública Federal traslada a 48 reos que se encontraban en centros de reinserción social del estado a diferentes penales federales del país. El traslado se lleva acabo como parte del programa de "reducción" de los centros penitenciarios. Entre los internos movilizados destaca el indígena Alberto Patishtán Gómez. Patishtán Gómez padece glaucoma, y sin importar tal condición, él es trasladado a una prisión federal ubicada en Guasave, Sinaloa a 2 kilómetros de distancia de donde estaba encerrado.

18 de marzo 2012.- Dos indígenas se "crucifican" en las afueras del poder Legislativo de Chiapas, como parte de la jornada de resistencia pacífica que realizan en demanda de la liberación de un grupo de reos procesados en diferentes penales del estado.

3 de octubre 2012.- La Suprema Corte de Justicia de la Nación (SCJN) revisará el incidente de reconocimiento de inocencia que promueve la defensa de Alberto Patishtán Gómez. El incidente es el último recurso legal de Patishtán, acusado de homicidio, lesiones calificadas, robo calificado, daños y portación de arma de fuego de uso exclusivo del Ejército mexicano.

30 de enero 2013.- En el penal de San Cristóbal de las Casas, nueve indígenas se declaran en huelga de hambre durante 7 días; uno de ellos es el tzotzil Alberto Patishtán Gómez.

5 de marzo 2013.- La Primera Sala de la Suprema Corte anuncia que un Juzgado en Chiapas determinará la inocencia de Alberto Patishtán.

9 El Universal, 2013. 
12 de marzo 2013.- El preso prozapatista Alberto Patishtán Gómez agradece a los ministros de la Suprema Corte de Justicia de la Nación, Olga Sánchez y Arturo Zaldívar Lelo de la Rea por "la decisión positiva" que tuvieron en asumir competencia en su caso.

21 de marzo 2013.- En reclamo de libertad, el profesor tzotzil Alberto $\mathrm{Pa}$ tishtán Gómez y una veintena más de internos inician una jornada de 7 días de ayuno, en el centro penitenciario de San Cristóbal de las Casas. La protesta pacífica es la etapa inicial de un movimiento que demanda la excarcelación del indígena, después de que la SCJN rechazó reasumir la revisión de su expediente penal.

27 de mayo 2013. - La Suprema Corte de Justicia de la Nación remite al Primer Tribunal Colegiado del Vigésimo circuito en Tuxtla Gutiérrez, el expediente penal del indígena Alberto Patishtán Gómez para su estudio y resolución final.

20 de agosto 2013.- El maestro indígena Alberto Patishtán inicia una jornada de ayuno y oración en el penal de San Cristóbal de las Casas como parte de una serie de manifestaciones que familiares y simpatizantes realizarán para que los magistrados del primer Tribunal Colegiado del vigésimo Circuito de Chiapas resuelvan el recurso de reconocimiento de inocencia.

12 de septiembre 2013.- Un tribunal en Tuxtla Gutiérrez niega la liberación del indígena tzotzil. Alberto Patishtán deberá permanecer en prisión, ya que el incidente de reconocimiento de inocencia que promovió su defensa no prosperó y se declaró infundado.

13 de septiembre 2013.- El gobernador Manuel Velasco Coello afirma que ante la resolución judicial que negó la libertad de Alberto Patishtán Gómez, "debe proceder el indulto".

25 de septiembre 2013.- Alberto Patishtán insiste en su inocencia y confía en obtener su libertad si el Senado promueve una Ley de Amnistía que facilite su salida del penal, donde cumple una sentencia por su supuesta participación en el asesinato de siete policías. El tzotzil afirma que "Ante los ojos de Dios, desde los primeros días en que me detuvieron soy inocente no he cometido nada y dentro de mi conciencia no le debo a nadie".

21 de octubre 2013. - La Comisión de Justicia del Senado aprueba una reforma para otorgarle al Presidente la facultad de aplicar el indulto a presos, cuando se tengan pruebas de violaciones a sus derechos humanos. La Comisión toma como referencia el caso de Alberto Patishtán quien está en la cárcel por varios delitos, pero se violaron sus derechos humanos y el debido proceso.

29 de octubre 2013. - Las reformas al Código Penal Federal para facultar al presidente en materia de indulto, son aprobadas por el pleno de la Cámara 
de Diputados con 442 votos, luego de dos horas de debate. Tras recibirla del Senado de la República y votarla, esta minuta fue enviada al Ejecutivo Federal para su promulgación y publicación; con ella se podría liberar por indulto al profesor indígena Alberto Patishtán.
29 de octubre 2013.- El presidente Enrique Peña Nieto anuncia que indultará al profesor tzotzil Alberto Patishtán Gómez. El presidente detalla que se publicarán en el Diario Oficial de la Federación las reformas al Código Penal Federal en materia de indulto aprobadas por el Congreso. 